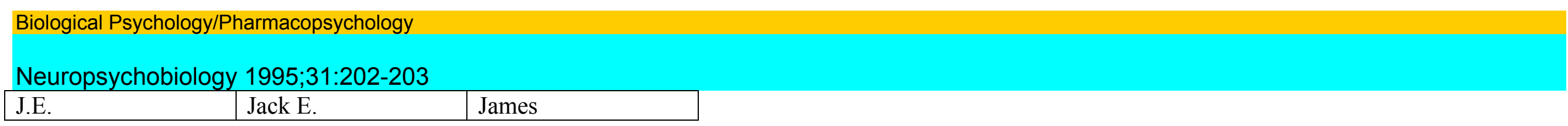

School of Behavioural Health Sciences, La Trobe University, Melbourne, Vic., Australia

\title{
Caffeine and Psychomotor Performance Revisited
}

Prof. Jack E. James, School of Behavioural Health Sciences, La Trobe University, Melbourne, Vic. 3083 (Australia)

In a recent commentary in this journal [1], I pointed out that several studies by Smith et al. [2-5] on caffeine and psychomotor performance are flawed because the investigators failed to control for the effects of caffeine withdrawal. In essence, because the subjects in these experiments were habitual consumers who had been without caffeine for some time prior to testing, improvements in performance following administration of the drug may simply have amounted to the restoration of performance already degraded by caffeine withdrawal. On the one hand, Smith [6] appears to accept this argument -in a passing reference, he reports that he and his colleagues are attempting to deal with the methodological flaw in their previous research by using an alternative experimental approach. On the other hand, Smith's [6] reply mostly takes the form of a rebuttal which tries to suggest that the effects of caffeine withdrawal are inconsequential, while improvements in performance following caffeine ingestion are marked. These suggestions, however, are inconsistent with the available evidence, and are at odds with the consensus of scientific opinion.

It is widely accepted that any enhancing effects of caffeine on psychomotor performance are at best small and unstable. For example, in a widely cited review, Dews [7] concluded that caffeine's effects on performance are too unreliable and capricious to be of any real importance. Similarly, Stavric [8] concluded that the effects are no more than 'very slight and subtle' [p. 655], and James [9] found that 'caffeine bestows little if any benefit on cognitive and psychomotor performance' [p. 272]. In light of the fact that these various reviews gave little attention to possible confounding arising from uncontrolled caffeine withdrawal (a flaw which is likely to have been present in much of the relevant empirical research), the inescapable inference is that the evidence for caffeine enhancement of psychomotor performance is even less reliable and more slight than the marginal potency granted in successive previous reviews.

In contrast, caffeine withdrawal is one of the most reliable phenomena associated with caffeine consumption in humans. The evidence has been extensively reviewed by Griffiths and his colleagues [10,11], and is very consistent. A wide array of effects is involved, including headache, drowsiness, decreased alertness, and impaired concentration. When experienced, the severity of effects may vary from 'mild to extreme', and may sometimes be 'totally incapacitating' [11]. One factor which limits direct comparisons between studies of the adverse effects of caffeine withdrawal and studies of performance enhancement following caffeine ingestion is that the two fields of enquiry have only infrequently used the same measurements. Nevertheless, there are a few examples involving directly comparable measurements, and results have confirmed that caffeine withdrawal may impair psychomotor performance (e.g. reaction time [12] and rate of finger tapping [13]). Overall, the evidence consistently shows that there is a difference in magnitude between the purported enhancing effects of caffeine ingestion and the totality of detrimental effects of caffeine withdrawal, with the latter being distinctly larger and more reliable. The suggestion by Smith [6] that his research deserves special attention, because the 'functions' that he and his colleagues have examined differ from performance

functions tested by other caffeine researchers is unwarranted. While the performance tests employed by Smith et al. [2-5] may have had some distinctive features (few investigators have used identical procedures), the functions these tests were designed to measure are essentially standard, including 'simple' reaction time, 'choice' reaction time, memory, and logical reasoning. Furthermore, although results similar to those reported by Smith et al. [2-5] have been reported by others, there has also been extensive reporting of caffeine either having no effect or harming performance across a wide range of functions $[9,14$, for review]. While the reasons for the many inconsistencies are not well understood, there is an emerging consensus regarding the functions that are not assisted by caffeine. Briefly, performance enhancement has generally been reported in relation to monotonous and repetitive tasks requiring continuous attention, whereas tasks involving more complex cognitive processes are more likely to be harmed by caffeine [9,14]. Thus, the controversy about possible beneficial effects is not whether these effects are general (there seems little doubt that they are not), but whether beneficial effects exist at all in relation to relatively simple and repetitive psychomotor activity. The claims by Smith et al. [2] that exposure to caffeine produces 'great' and 'global benefits' are unfounded. 
In a separate article in this journal, Rogers et al. [15] have argued the case for caffeine having a 'net' beneficial effect on psychomotor performance. While they appear to be implying more modest effects than claimed by Smith et al. [2], Rogers et al. [15] nevertheless possibly underestimate some important considerations. In particular, they

(C) 1995

S. Karger AG, Basel

0302-282X/95/0314-0202

$\$ 8.00 / 0$

give little attention to the negative evidence (i.e. the many studies that have reported either no effect or adverse effects of caffeine on psychomotor performance) and the circumscribed nature of the benefits when these have been reported (i.e. whatever benefits have been reported have generally been limited to simple and repetitive tasks) [7-9, for review]. In addition, while acknowledging the generalised impairment caused by caffeine withdrawal, they state that they are unaware of studies demonstrating that caffeine withdrawal may impair psychomotor performance specifically. As mentioned above, there is such evidence $[12,13]$.

Notwithstanding these omissions, I agree with the suggestion [15] that future research should aim to assess the effects of caffeine on performance in natural settings. Were such studies to be done (e.g. in the work place) they should aim to be as ecologically valid as is practicable, including in particular an appropriate time frame and repeated exposure to caffeine (to allow for the separate assessment and control of caffeine withdrawal effects and the development of tolerance). In

the absence of such research, my contention is that the available evidence suggests that any net benefit of caffeine in humans is slight at best (but, of course, a definitive answer must await completion of the required naturalistic studies). The implication that caffeine might be a useful pharmacological tool for managing work place productivity [2] is unwarranted, especially when there are alternative strategies (e.g. intermittent brief rest periods [ 16]) that are likely to be more effective whole not incurring any risks of adverse side-effects.

Finally, to return to the main purpose of my earlier critique [1], part of the concern arising out of unwarranted claims about caffeine benefits is the potential misuse to which such claims may be put. Caffeine, as consumed in coffee, tea, and cola soft drinks, is the most widely used psychoactive substance in the world, and the production, distribution, and sale of caffeine products are multinational, multibillion-dollar enterprises. It is accepted within the caffeine industry that public knowledge of caffeine-induced deleterious effects is commercially

damaging, and the industry has invested considerable resources to counteract such threats $[17,18]$. Conversely, commercial interests are likely to be advanced by claims of beneficial effects, and Smith's opinions have indeed been selected by caffeine industry bodies for public dissemination [19]. Accordingly, apart from the usual scientific imperatives, concern for the public interest demands that the purported benefits of caffeine are appaised with the utmost care. As argued previously [1], studies by Smith et al. [2-5] have not demonstrated caffeine-induced enhancement of psychomotor performance, because the studies in question failed to control for the effects of caffeine withdrawal. Smith's [6] rejoinder cannot be sustained, because (a) the overall evidence suggests that the benefits (if any) of caffeine on psychomotor performance are slight at best [7-9], and (b) contrary to Smith's claims [2, 6], caffeine withdrawal causes decrements in performance and well-being in a large proportion of consumers [11].

References

James JE: Does caffeine enhance or merely restore degraded psychomotor performance? Neuropsychobiology 1994;30:124-125.

Smith AP, Brockman P, Flynn R, Maben A, Thomas M: Investigation of the effects of coffee on alertness and performance during the day and night.

Neuropsychobiology 1993;27: 217-223.

Smith AP, Kendrick AM, Maben AL: Effects of breakfast and caffeine on performance and mood in the late morning and after lunch. Neuropsychobiology 1992;26:198-204.

Smith AP, Rusted JM, Eaton-Williams P, Savory M, Leathwood P: Effects of caffeine given before and after lunch on sustained attention.

Neuropsychobiology 1990;23:160-163.

Smith AP, Rusted JM, Savory M, Eaton-Williams P, Hall SR: The effects of caffeine, impul-sivity and time of day on performance, mood and cardiovascular function. J Psychopharma-coll991;5:120-128.

Smith AP: Caffeine, caffeine withdrawal and psychomotor performance: A reply to James. Neuropsychobiology 1995;31:200-201.

Dews PB: Behavioral effects of caffeine; in Dews PB (ed): Caffeine: Perspectives from Recent Research. Berlin, Springer, 1984, pp 86-103.

Stavric B: Methylxanthines: Toxicity to Humans. 2. Caffeine. Food Chem Toxicol 1988; 26:645-662.

James JE: Caffeine and Health. London, Academic Press, 1991. 
Griffiths RR, Woodson PP: Caffeine physical dependence: A review of human and laboratory animal studies. Psychopharmacology (Berlin) 1988;94:437451.

Griffiths RR, Mumford GK: Caffeine - a drug of abuse? in Bloom FE, Kupfer DJ (eds): Psychopharmacology: The Fourth Generation of Progress. New York, Raven Press, 1995; pp 1699-1713.

Rizzo AA, Stamps LE, Fehr LA: Effects of caffeine withdrawal on motor performance and heart rate changes. Int J Psychophysiol 1988;6: 9-14.

Silverman K, Evans SM, Strain EC, Griffiths RR: Withdrawal syndrome after the double-blind cessation of caffeine consumption. N Engl J Med 1992;327:1 109-1114.

van der Stelt O, Snel J: Effects of caffeine on human information processing: A cognitive-energetic approach; in Garattini S (ed): Caffeine, Coffee, and Health. New York, Raven Press, 1993, pp 291-316.

Rogers PJ, Richardson NJ, Dernoncourt C: Caffeine use: Is there a net benefit for psychomotor performance? Neuropsychobiology 1995;31:in press.

Loke WH, Meliska CJ: Effects of caffeine use and ingestion on a protracted visual vigilance task. Psychopharmacology 1984;84:54-57.

James JE: Caffeine, health and commercial interests. Addiction 1994;89:1595-1599.

James JE: Caffeine, health and commercial interests: Reply to Golding. Addiction 1995;90: in press

James JE: Caffeine, health and commercial interests: Reply to Smith. Addiction 1995;9O:in press.

203Letter to the Editor 